\title{
Satellite remote sensing of water turbidity in Alqueva reservoir and implications on lake modelling
}

\author{
M. Potes ${ }^{1}$, M. J. Costa ${ }^{1,2}$, and R. Salgado ${ }^{1,2}$ \\ ${ }^{1}$ Évora Geophysics Centre (CGE), University of Évora, Rua Romão Ramalho 59, 7000-671 Évora, Portugal \\ ${ }^{2}$ Department of Physics, University of Évora, Rua Romão Ramalho 59, 7000-671 Évora, Portugal
}

Correspondence to: M. Potes (mpotes@uevora.pt)

Received: 7 October 2011 - Published in Hydrol. Earth Syst. Sci. Discuss.: 21 December 2011

Revised: 23 April 2012 - Accepted: 11 May 2012 - Published: 6 June 2012

\begin{abstract}
The quality control and monitoring of surface freshwaters is crucial, since some of these water masses constitute essential renewable water resources for a variety of purposes. In addition, changes in the surface water composition may affect the physical properties of lake water, such as temperature, which in turn may impact the interactions of the water surface with the lower atmosphere.

The use of satellite remote sensing to estimate the water turbidity of Alqueva reservoir, located in the south of Portugal, is explored. A validation study of the satellite derived water leaving spectral reflectance is firstly presented, using data taken during three field campaigns carried out during 2010 and early 2011. Secondly, an empirical algorithm to estimate lake water surface turbidity from the combination of in situ and satellite measurements is proposed. Finally, the importance of water turbidity on the surface energy balance is tested in the form of a study of the sensitivity of a lake model to the extinction coefficient of water (estimated from turbidity), showing that this is an important parameter that affects the lake surface temperature.
\end{abstract}

\section{Introduction}

Water quality of reservoirs is determined by physical and chemical properties. Thus, the success of reservoir management depends on the detection of spatial and temporal changes in the reservoir status that reflect natural and anthropogenic alterations in the surrounding environment (Chapman, 1996; Lee and Walter, 1997; Morais et al., 2007). Lakes strongly affect the structure of the atmospheric boundary layer (see, for example, Zilitinkevich et al., 1991) and therefore the weather and the climate on a variety of scales. However, until very recently, the numerical weather prediction (NWP) models did not include an explicit representation of the evolution of lake properties. Currently, many efforts are being made to include 1-D lake parameterization schemes in operational numerical weather prediction (NWP) models (e.g. Mironov et al., 2010; Salgado and Le Moigne, 2010; Dutra et al., 2010). The two layer bulk lake model, FLake (Mironov, 2008), enjoys growing popularity in NWP and climate models as well as in limnology. Examples of the impact of the inclusion of these schemes on weather forecast and climate models can be found in Balsamo et al. (2012) and Kheyrollah Pour et al. (2012) and references therein. The FLake model includes the following optical parameters: surface albedo, long wave emissivity and light extinction coefficient. The water extinction coefficient only rarely is directly measured. On the contrary, there are some studies aiming at relating turbidity measurements with extinction coefficients (Parkhill and Gulliver, 2002; Giblin et al., 2010); nevertheless, these relationships depend on the water mass conditions (combination of organic and inorganic material present in the water mass).

Turbidity is an optical property of the water body - a measure of the amount of light scattered and absorbed by particles in the water column (Michaud, 1991). Turbidity may induce changes in the lake's vertical thermal structure, which in turn plays an important role in autochthonous primary production (Friedl and Wüest, 2002) and in the evolution of the water surface temperature, which is a key variable in the water-atmosphere transfers.

Turbidity is frequently measured in many lakes and reservoirs since it is included in the water quality monitoring 
programs. However, samples regularly collected and analysed in the laboratory are spatially and temporally limited. Thus, the use of satellite data to evaluate the optical water properties is steadily increasing, since this kind of data provides undoubtedly the only way to proceed for global characterization of reservoirs (Koponen et al., 2002; Chen et al., 2006; Tyler et al., 2006; Simis et al., 2007; Alikas and Reinart, 2008; Duan et al., 2008; Gitelson et al., 2008; Gons et al., 2008).

According to Moore (1980), the feasibility of measuring water color and turbidity from satellites can be assessed by considering light and water interaction processes and by evaluating the effects of atmospheric and hydrological variables. Note that the many Low Earth Orbit satellite instruments launched in the last decade constitute exceptionally valuable tools for quantitative analysis of surface water quality (Gordon and Wang, 1994; Dickey et al., 2006). Their multi-spectral and spatial resolution capabilities allow for improved techniques in retrieving the optical properties of lake water. A good example is the MEdium Resolution Imaging Spectrometer (MERIS) onboard ENVIronmental SATellite (ENVISAT), which combines moderately high spatial resolution $(260 \mathrm{~m} \times 290 \mathrm{~m}$ at nadir) with an adequate spectral resolution in the visible and near infra-red regions (ESA, 2008). Higher spatial resolution satellite systems are available, but there are difficulties associated with their use: on one hand their long revisit cycle and on the other hand the related expenses. The use of MERIS represents a good compromise in order to have a low-cost, frequent (nominal revisit time of 2-3 days at midlatitudes) monitoring of inland water bodies. The potential of using satellite remote sensing data to obtain information on lake water turbidity is demonstrated in this work.

Potes et al. (2011) recently developed a method to retrieve surface freshwater biological parameter (chlorophyll $a$ and cyanobacteria) concentrations over Alqueva reservoir (south of Portugal) from MERIS satellite data, aiming at providing full spatial coverage and continuous monitoring of these parameters that affect the water quality. The methodology is now adapted and presented here to obtain a new empirical algorithm allowing for the retrieval of the water turbidity of the same reservoir, which is important for the estimation of water extinction coefficients.

The present work has three main goals: firstly, the validation of the atmospheric correction methodology; secondly, the development of a satellite-based remote sensing method to retrieve surface inland freshwater turbidity, which is a measure of water quality characterizing optical behavior and deemed an essential parameter towards the improvement of lake parameterization schemes in weather forecast and climate models; and thirdly, as a natural consequence of the previous aim, it is an objective of this work to show the importance of the lake optical characteristics in the evolution of lake surface temperature and heat fluxes. This is done through a sensitive analysis of the FLake model results to different values of the water extinction coefficient, representing here possible extreme water turbidity cases.

The following section gives a description of the data and methods used. Sects. 3 and 4 present the results and Sect. 5 summarizes the conclusions.

\section{Study site, data and methods}

The Alqueva reservoir, located in the south of Portugal along $83 \mathrm{~km}$ of the main course of the Guadiana River, constitutes the largest artificial lake in the Iberian Peninsula (Fig. 1). At the full storage level of $152 \mathrm{~m}$, the reservoir has a total capacity of $4.150 \mathrm{~km}^{3}$ and a surface area of $250 \mathrm{~km}^{2}$. Filling of Alqueva reservoir began in February 2002 and lasted about one year to reach a stable storage level of about $135 \mathrm{~m}$.

According to Morais et al. (2007), Alqueva reservoir was classified as eutrophic based on total phosphorus $\left(>35 \mathrm{mg} \mathrm{P} \mathrm{m}^{-3}\right)$ and chlorophyll $a\left(<10 \mu \mathrm{gl}^{-1}\right)$ concentrations. The Alqueva water quality control belongs to a large monitoring programme implemented by the Portuguese company responsible for Alqueva exploitation (Empresa de Desenvolvimento e Infra-Estruturas de Alqueva, EDIA). The monitoring programme was implemented at the beginning of the filling phase. Nevertheless, this control is spatially and temporally limited. Monthly water samples are collected in a few spots of the reservoir, and afterwards analyzed in laboratory. Two sites were selected (up to $500 \mathrm{~m}$ from the shore) for the validation presented in this study, taking into account not only their geographical positions inside the reservoir, but also the corresponding satellite image pixel dimensions $(260 \times 290 \mathrm{~m})$ that should enclose a homogeneous surface. Figure 1 illustrates the location of these sites, namely Mourão and Montante. The selection of these sites aims, in addition, to reduce as much as possible the adjacency effects, consisting of the brightening of dark water pixels due to reflections from neighboring land (vegetation or soil) pixels with higher reflectances, which reach the sensor and appear to come from a water pixel, thereby reducing the contrast between water and land pixels.

In March 2002 the European Space Agency (ESA) launched ENVISAT (ENVIronmental SATellite), an advanced polar-orbiting Earth observation satellite which provides complete coverage of the globe within one to three days (ESA, 2008).

The MEdium Resolution Imaging Spectrometer (MERIS), onboard ENVISAT, measures the solar reflected radiation from the Earth, ranging from the visible to the near infrared (400 to $1040 \mathrm{~nm}$ ). These spectral bands were carefully chosen in accordance with the mission goals and priorities of the MERIS instrument, to ensure practical applicability of the sensor.

MERIS full resolution (FR) level 1 imagery are used, corresponding to spectral top of the atmosphere (TOA) radiances for each of the MERIS spectral channels, with the 


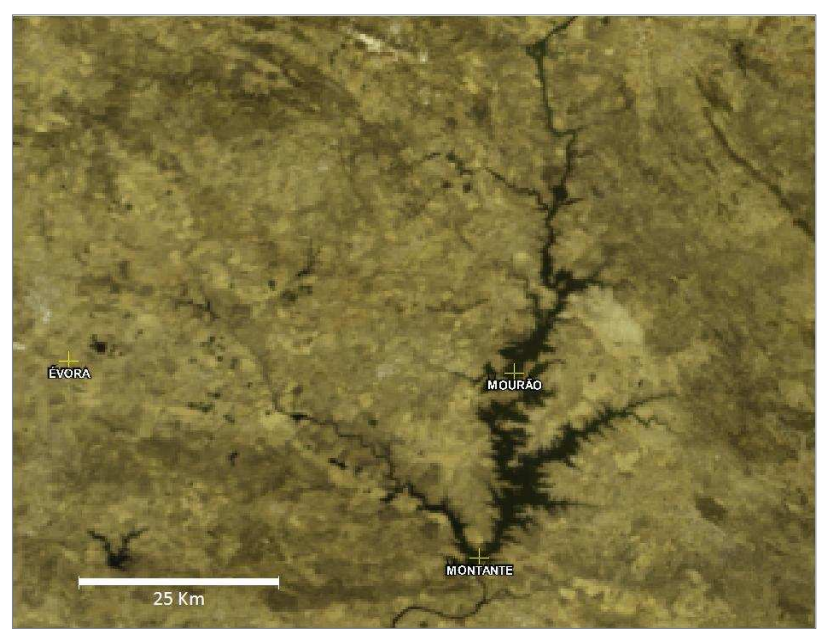

Fig. 1. MERIS image showing Alqueva reservoir location and position of the sites used in the study. The city of Évora is also indicated as a point of reference.

maximum spatial resolution of $260 \times 290 \mathrm{~m}$ at the nadir. The selection of the MERIS images was based on three conditions: (i) minimum time lag between MERIS and limnological sampling dates, due to possible alterations of the water surface parameters (one day difference); (ii) cloud-free conditions (MERIS cloud mask); and (iii) lack of aerosol events (generally desert dust or forest fire smoke). A water mask is applied to identify inland waters pixels from Alqueva reservoir. The test relies on the TOA (top of the atmosphere) spectral reflectances, with the conditions that band $6(620 \mathrm{~nm})>$ band $10(753.75 \mathrm{~nm})$ and band 13 $(865 \mathrm{~nm})<0.1$.

\subsection{Atmospheric correction validation}

The assessment of the retrieval reliability is highly dependent on the comparison with independent measurements that allow for error estimation and eventually achieve a validation of the method (Dickey et al., 2006). The study of surface water properties from satellite remote sensing techniques requires the correction of atmospheric effects. The present study is applied only to cloud-free days over Alqueva reservoir. Major gas absorption bands are avoided as well; therefore, the atmospheric correction depends essentially on the type and amount of aerosols present in the atmosphere. Aerosol event situations are also discarded, and thus only clean background aerosol conditions are being considered (Elias et al., 2006). A comprehensive description of the atmospheric correction methodology used is given by Potes et al. (2011). The aerosol measurements (optical thickness, size distribution, and complex refractive index) continuously taken at the observatory of the Évora Geophysics Centre (CGE), as part of the AErosol RObotic NETwork (AERONET) (Holben et al., 2001), are used in the atmospheric correction. This is done assuming that there is not a significant variation in the aerosol conditions between Évora and the Alqueva area (horizontal distance of about $50 \mathrm{~km}$ ); most of the time this is an accurate approximation, except in the case of aerosol events (Elias et al., 2006). The radiative transfer code adopted for the atmospheric correction was the Second Simulation of the Satellite Signal in the Solar Spectrum (6S) developed by Vermote et al. (1997). The $6 \mathrm{~S}$ can simulate satellite radiation measurements in cloudfree atmospheres between 0.25 and $4.0 \mu \mathrm{m}$, for a wide range of atmospheric and surface conditions, taking into account the main atmospheric compounds and considering 34 atmospheric levels distributed from the ground up to $100 \mathrm{~km}$ altitude. The adjacency effects due to reflection from contiguous pixels are also taken into account in the algorithm (considering water, and vegetation or soil surface) according to the neighbouring pixel classifications (Potes et al., 2011).

During 2010 and 2011 three field campaigns were carried out in Alqueva reservoir to measure the water leaving spectral reflectance, with the aim of validating the satellite atmospherically corrected spectral reflectance. A portable spectroradiometer (FieldSpec UV/VNIR) from ASD Inc. was used for this purpose, and the water leaving spectral reflectance was measured across the spectral range $325-1075 \mathrm{~nm}$ with 1 to $3 \mathrm{~nm}$ spectral resolution from visible to near infrared. The campaigns took place at Mourão site on 27 July 2010, Mourão and Montante sites on 25 August 2010 and at three distinct places near Mourão site on 24 February 2011.

Figure 2 shows a comparison between the measured and satellite-derived water leaving reflectance, obtained for the three field campaigns carried out. The measured spectrum is identified as FieldSpec (solid line) and it corresponds to the average of ten measured spectra. The different satellitederived spectra correspond to the: (i) atmospheric correction developed by the authors (Potes et al., 2011), hereinafter referred to as MERIS L1+6S; (ii) MERIS level 1b lake algorithm (Doerffer and Schiller, 2008), referred to as MERIS LA; and (iii) MERIS level 2, identified as MERIS L2. Note that the atmospheric correction scheme developed by the authors (MERIS L1+6S) is the one that better matches the measured water leaving reflectance for the three campaigns carried out. In Fig. 2c the MERIS L1+6S spectrum for Mourão 2 presents high values of reflectance in the near-infrared spectral region, which can be attributed to the lesser distance from shore with respect to Mourão 1 and 3, resulting in the contamination of the MERIS pixel by vegetation present in the nearby land pixels in this period of the year.

Table 1 presents the statistical parameters of the regressions obtained for each of the campaigns, considering the MERIS L1+6S retrieval and the field measurements. The data points for each campaign correspond to the number of spectral bands available from the MERIS images for each of the sites where measurements are taken.

On 25 August 2010 a good agreement between groundbased measurements and satellite retrievals was obtained, 
Table 1. Parameters obtained in the correlation between the measured and satellite-derived water leaving spectral reflectance (MERIS L1+6S) for the three field campaigns carried out. The parameters are the following: number of data $(N)$, equation of the regression, correlation coefficients $(R)$, root mean squared errors (RMSE) and normalized root mean squared errors (NRMSE).

\begin{tabular}{lclccc}
\hline Campaign date & $N$ & Regression equation & $R$ & RMSE & NRMSE (\%) \\
\hline 27 July 2010 & 14 & $0.73 x+0.012$ & 0.64 & 0.01 & 46 \\
25 August 2010 & 30 & $1.04 x-0.0007$ & 0.96 & 0.002 & 8 \\
24 February 2011 & 45 & $0.77 x+0.008$ & 0.87 & 0.007 & 16 \\
\hline
\end{tabular}

Table 2. Parameters obtained in the correlation between the measured and satellite-derived water leaving spectral reflectance for the three methods that are compared. The parameters are the same as in Table 1.

\begin{tabular}{lclccc}
\hline Method & $N$ & Regression equation & $R$ & RMSE & NRMSE (\%) \\
\hline MERIS L1+6S & 89 & $0.86 x+0.0050$ & 0.84 & 0.007 & 14 \\
MERIS L2 & 78 & $0.28 x-0.0003$ & 0.27 & 0.020 & 33 \\
MERIS LA & 72 & $-0.08 x+0.0060$ & -0.21 & 0.012 & 27 \\
\hline
\end{tabular}

with a correlation coefficient of 0.96 and a normalized root mean squared error of $8 \%$. A slightly worse agreement was found for 27 July 2010, with a correlation coefficient of 0.64 and a normalized root mean squared error of $46 \%$; nonetheless, the linear correlation was still significant for a $95 \%$ confidence interval. In fact, on 27 July 2010 a minor desert dust transport event was starting to affect the area with aerosol optical depths (at $440 \mathrm{~nm}$ ) that reached 0.26 , whereas for clean background situations the aerosol optical depth at $440 \mathrm{~nm}$ is lower than 0.12 (Elias et al., 2006). In these cases the atmospheric conditions can hardly be considered spatially homogeneous, therefore the situation between Évora (where the aerosol measurements are taken) and Alqueva may be somewhat different and the atmospheric correction results reflect this. On 24 February 2011, MERIS FR image data was not available due to issues connected with ESA acquisition strategy; therefore the satellite image used in this campaign is the MERIS reduced resolution (1200 $\mathrm{m}$ at nadir). The major problems arising in this case are mainly connected to pixel dimension, and since Alqueva is not a very large lake, the difficulties associated with adjacency effects increase. Nevertheless, a correlation coefficient of 0.87 and a normalized root mean squared error of $16 \%$ were found. In summary, measurements were taken at six sites during the three field campaigns: Mourão site on 27 July 2010, Mourão and Montante sites on 25 August 2010 and three distinct places near Mourão site on 24 February 2011. MERIS L1+6S has 15 spectral bands which would supply a total of 90 points; nevertheless, atmospheric correction failed for one of the data points (the reflectance was negative) and therefore 89 data points were available. MERIS L2 is provided with 13 spectral bands which give a total of 78 data points. MERIS algorithm from Doerffer and Schiller (2008) is provided with 12 spectral bands summing 72 points. Table 2 summarizes the statistical parameters of the regressions obtained for each of the three atmospheric correction methods considered. It should be noted that the atmospheric correction applied according to the methodology proposed by Potes et al. (2011) (MERIS L1+6S) presents the best fit with FieldSpec measurements, with a correlation coefficient of 0.84 , whereas both MERIS L2 and LA present pretty low correlation coefficients of 0.27 and -0.21 , respectively. Also the NRMSE values for the latter two methods (33\% and $27 \%$ ) are about twice the value obtained for MERIS L1+6S, which is $14 \%$. Since the empirical algorithm presented in next section is band-specific (i.e., uses bands centred at $412.5 \mathrm{~nm}$ and $560 \mathrm{~nm}$ ), the correlation coefficients and NRMSE are also calculated using only these two spectral bands. MERIS L1+6S presents once again the highest correlation coefficient with a value of 0.93 and a NRMSE of $16 \%$, whereas MERIS L2 and LA present correlation coefficients of 0.79 and 0.87 and NRMSE of 65 and $49 \%$, respectively. These results hint at the need for a specific atmospheric correction in the Alqueva area, allowing the use of water leaving spectral reflectances to accurately estimate water quality related parameters.

\subsection{Empirical algorithm}

The water leaving spectral reflectance obtained through atmospheric correction of TOA satellite data is related with in situ measurements of water turbidity, resulting in an algorithm which allows for the estimation of the water turbidity based upon the ratio of spectral reflectances (Bukata et al., 1995; Sathyendranath, 2000). This kind of technique was proposed before by Koponen et al. (2002) to monitor water turbidity in Finnish Lakes, and Chen et al. (2006) has applied a similar methodology in Tampa Bay (Florida, USA).

The data used for this purpose refers to the period 20072008 for Mourão and Montante sites (Fig. 1). The best retrieval algorithm was found empirically by deriving a regression model for all possible channels and channel ratio 

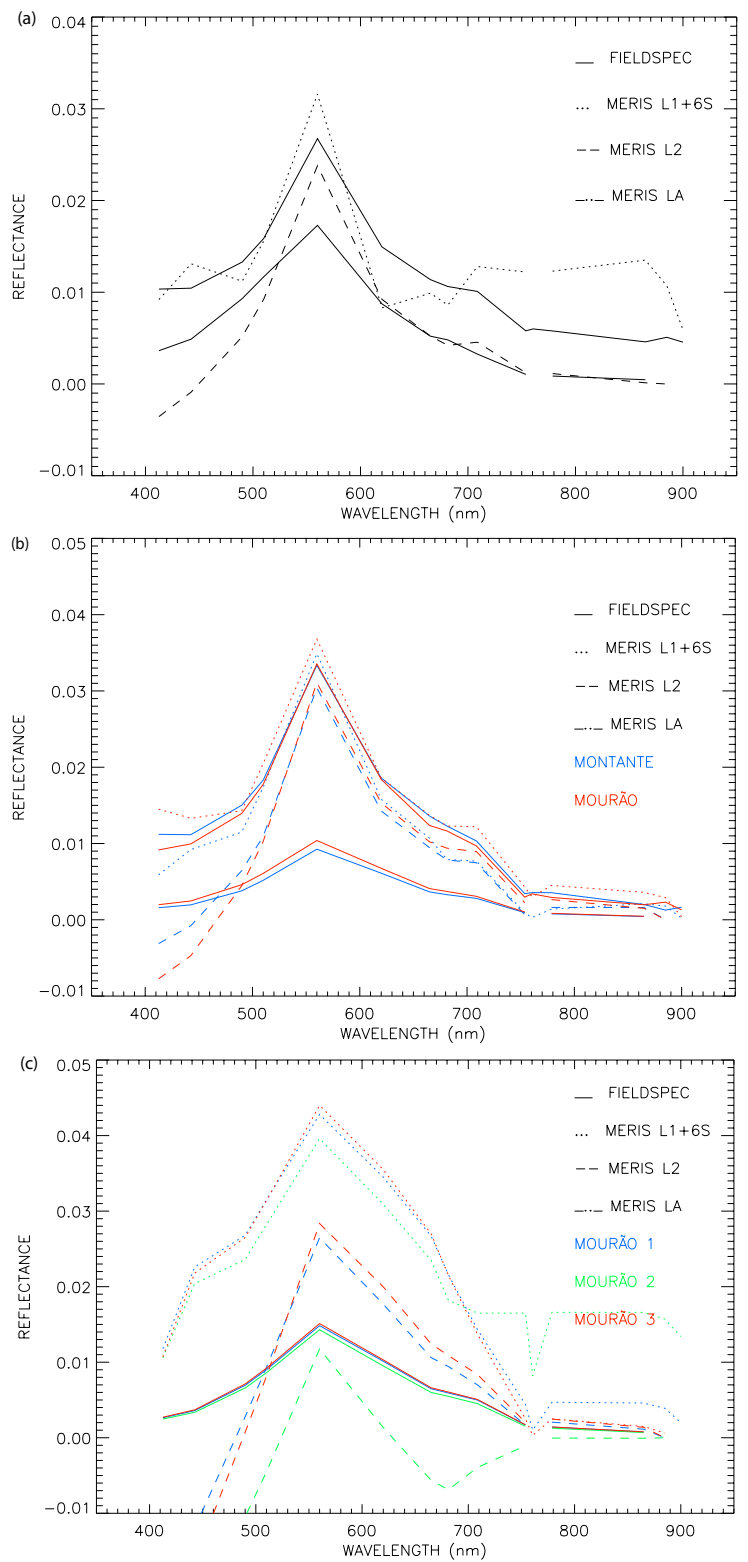

Fig. 2. Comparison between the measured and satellite-derived water leaving reflectance spectra for the three field campaigns: (a) 27 July 2010, (b) 25 August 2010 and (c) 24 February 2011. The measured spectra are identified as FieldSpec (solid line) and the satellite-derived are MERIS L1+6S (dotted), MERIS L2 (dashed) and MERIS LA (dash dot dot).

combinations and selecting the one with the highest correlation coefficient. The algorithms proposed by Härmä et al. (2001), Koponen et al. (2002) and Chen et al. (2006) found in the red and near infrared spectral bands the best fits, and consequently the empirical algorithms to retrieve water turbidity. Yet, in this study, the best fit found uses a ratio between green and blue spectral regions. The sensitivity to different spectral regions may be explained by the characteristics of the turbidimeter employed to measure water turbidity in Alqueva, which uses a tungsten lamp operating between 400 and $600 \mathrm{~nm}$, the same spectral range found to be the best combination for the empirical algorithm. The best fit between in situ water turbidity and atmospherically corrected satellite spectral reflectance combinations was revealed to be of linear type using the ratio between the green $(560 \mathrm{~nm})$ and blue $(412.5 \mathrm{~nm})$ MERIS spectral bands, with a rather high correlation coefficient of 0.96 (Fig. 3). A total number of 17 data points are used, corresponding to the two locations considered (Fig. 1) and to the period of study, taking into account the conditions imposed for the MERIS image selection (cloud-free sky, lack of aerosol events and minimum time lag between MERIS and limnology dates).

Note that the highest turbidity point of almost 60 NTU (Fig. 3), recorded at Mourão site, plays an important role in the linear correlation found (0.96); nevertheless, if the referred point is removed from the dataset, the linear correlation is still significant for a $99 \%$ confidence interval $(R=0.82)$. The empirical algorithm obtained is then used to estimate the water turbidity over the whole Alqueva reservoir surface area, as exemplified in Sect. 3.

In general, light intensity declines exponentially with depth, as described by the Beer-Lambert Law:

$I_{z}=I_{0} e^{-k z}$

where $I_{z}$ is the light intensity at a depth $z$ below the surface, $I_{0}$ is the immediate sub-surface light intensity, $z$ is the depth interval between $I_{0}$ and $I_{z}$, and $k$ is the rate of attenuation of downwelling radiation, usually referred to as the extinction coefficient.

Several authors propose different equations relating water turbidity and extinction coefficients (Grobler et al., 1983; Lloyd et al., 1987; Roos and Pieterse, 1994; Oliver et al., 1999; Parkhill and Gulliver, 2002; Giblin et al., 2010). Nine different relationships were analyzed (eight linear and one of quadratic type) and applied to the turbidity measurements taken in Alqueva reservoir in order to estimate the extinction coefficients. The minimum and maximum mean values obtained were 1.0 and $6.1 \mathrm{~m}^{-1}$, respectively, with greater dispersion found for the upper limit of the water extinction coefficients estimated; hence, the sensitivity study was conducted using these two values as lower and upper limits. Although these values are obtained for different conditions than those of Alqueva reservoir, they represent typical values of extinction coefficients for clean and turbid waters and indicate possible minimum and maximum values expected for Alqueva. Thus, these values are deemed suitable to carry out a sensitivity analysis on the surface water temperature and wateratmosphere heat fluxes. 


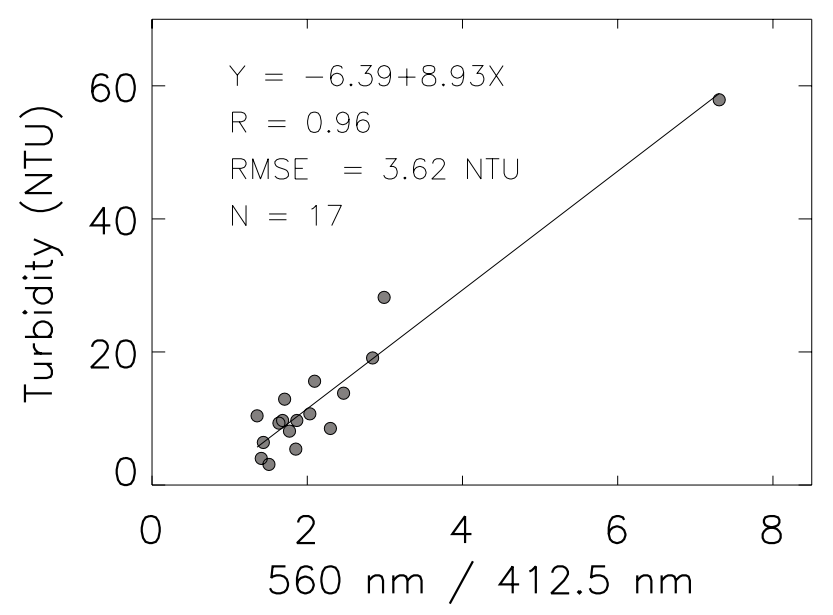

Fig. 3. Scatter plot between water turbidity (NTU) and the ratio between MERIS band $5(560 \mathrm{~nm})$ and band $1(412.5 \mathrm{~nm})$. Also shown the linear regression obtained.

\subsection{FLake model}

The FLake model, fully documented in Mironov (2008), is intended for use as a lake parameterization scheme in numerical weather prediction, climate modelling, and other numerical prediction systems for environmental applications. It is based on a two-layer representation of the evolving temperature profile and on the integral energy budgets for the two layers. The structure of the stratified layer between the upper mixed layer and the basin bottom, the lake thermocline, is described using the concept of self-similarity of the temperature-depth curve. This concept, based on empirical evidence with some theoretical support, assumes that the dimensionless temperature $\Phi$ profile in the thermocline can be fairly accurately parameterized through a universal function of dimensionless depth:

$\Phi(\zeta)=\frac{T_{\mathrm{S}}-T(z)}{T_{\mathrm{S}}-T_{\mathrm{BOT}}} ; \zeta=\frac{z-h}{D-h}$

where $z$ is the depth, $T_{\mathrm{S}}$ is the mixed-layer surface temperature, $T_{\mathrm{BOT}}$ is the temperature at the lake bottom, $h$ is the thickness of the mixed-layer, and $D$ is the total lake depth. $(D-h)$ is the thermocline depth. Several polynomial approximations for $\Phi$ may be found in the literature (see Mironov, 2008). In FLake, a 4th order polynomial is assumed for $\Phi$, and its shape is completely defined by its integral between $\zeta=0$ and $\zeta=1$, which is the shape factor, $C_{T}$. The dimensionless shape factor varies between a minimum value, 0.5 , corresponding to a mixed layer stationary state or retreat, and a maximum value, 0.8 , the maximum allowed curvature in the mixed layer deepening process. With this assumption, the water temperature profile is completely described by the four variables: $T_{\mathrm{S}}, T_{\mathrm{BOT}}, h$ and $C_{T}$; and one fixed parameter: $D$.

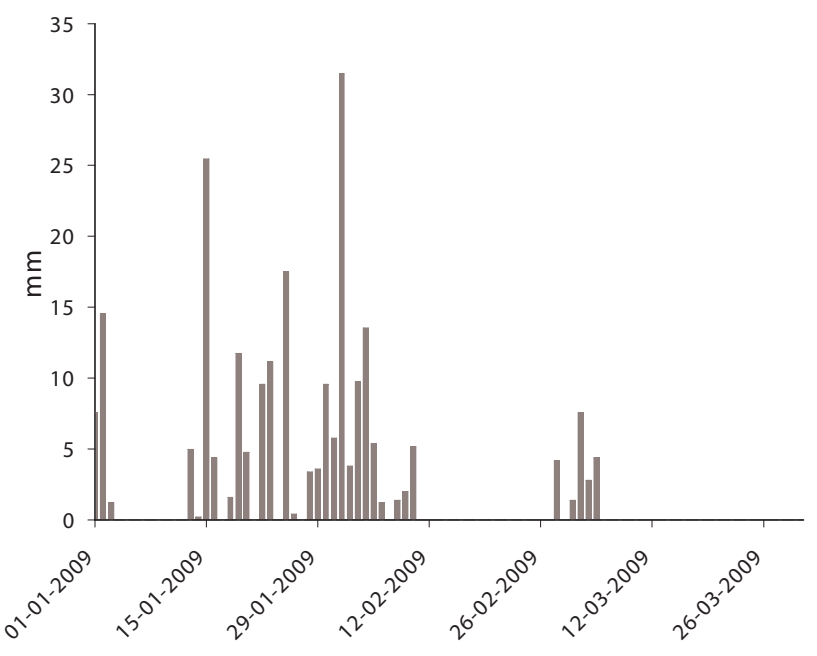

Fig. 4. Daily precipitation recorded in Évora Geophysics Centre, from January to March 2009.

In order to solve the energy balance equations for the two layers, the short-wave radiative flux is computed using the exponential approximation of the decay law (Eq. 1). The light extinction coefficient in water ( $k$ in Eq. 1), similar to other optical characteristics of water, is lake-specific and time dependent, and should hence be estimated with caution in every particular case. Up to 8 spectral bands characterized by different extinction coefficients may be considered in FLake.

The FLake model also includes optional schemes for the representation of upper layers of ice and snow and a bottom layer of sediments. The first ones were not activated in the present work as lake waters do not freeze in the region. The evolution of the vertical temperature structure of the thermally active layer of bottom sediments is computed using the same concept of self-similarity.

\section{Case study results}

A nearly continuous precipitation event that occurred during January and the first week of February 2009 (Fig. 4), in the south of Portugal, with roughly $210 \mathrm{~mm}$ of accumulated precipitation in 41 days, was recorded at Évora-Verney Meteorological station (Évora Geophysics Centre). Strong and continuous precipitation in the area causes a run-off, mainly by the Guadiana River, which usually introduces organic and inorganic matter into Alqueva reservoir, leading to an increase of water turbidity.

This effect is explored in the maps of turbidity shown in Fig. 5a and b, obtained by applying the developed algorithm (Fig. 3) to the whole Alqueva reservoir area. It can be clearly noticed that on 11 February 2009 (just after the precipitation event) the reservoir presents, in general, high turbidity values ( $>30 \mathrm{NTU})$ in comparison with the results obtained for 

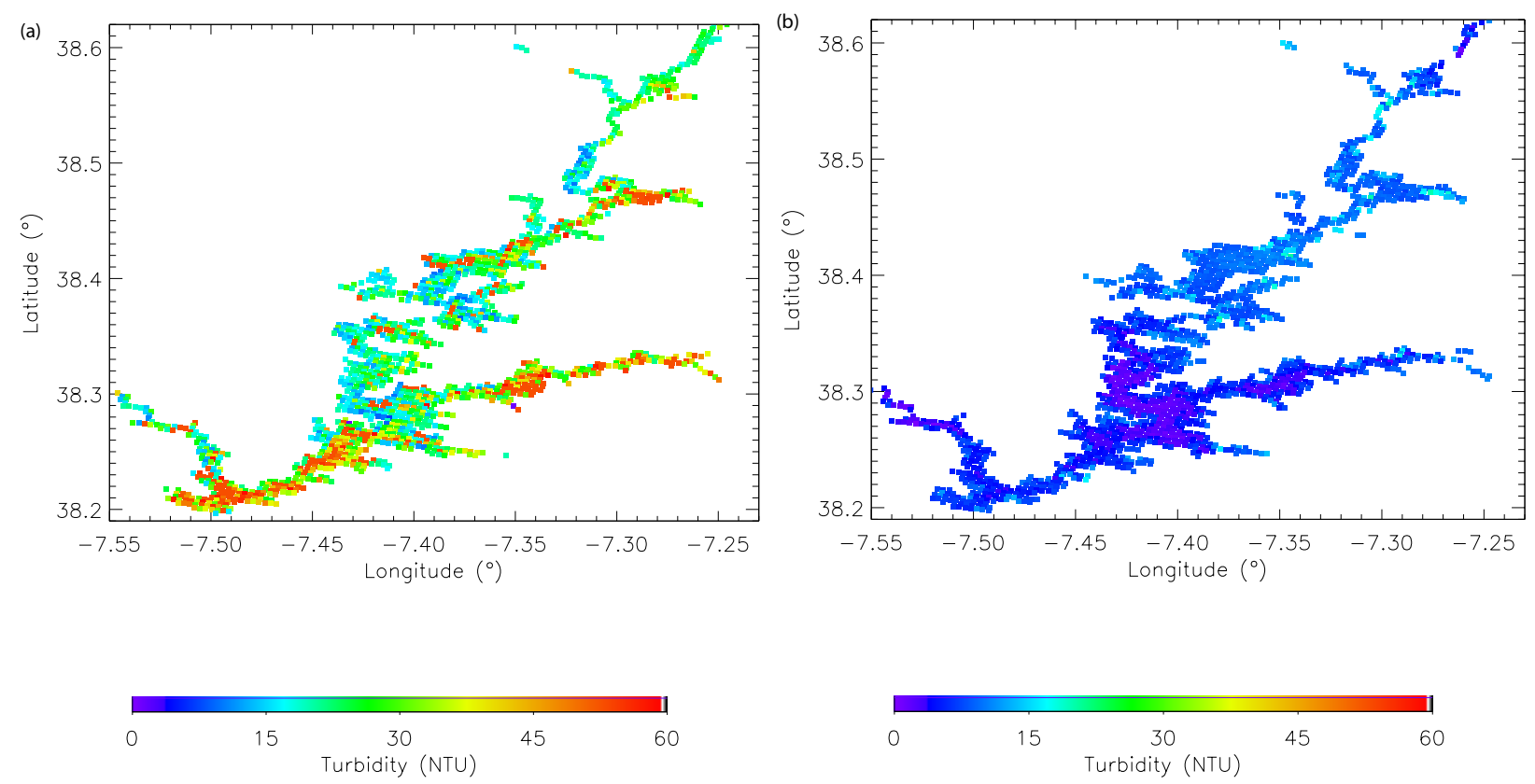

Fig. 5. Turbidity maps for Alqueva reservoir on (a) 11 February 2009 and (b) 15 March 2009.

15 March 2009 (1 month after the precipitation event), where the lake presents rather low turbidity values $(<10 \mathrm{NTU})$.

These results constitute a strong indication that the empirical algorithm derived provides meaningful turbidity values. Further turbidity measurements, which are not available presently, will extend the turbidity limits, strengthen the correlation and validate the empirical algorithm.

\section{FLake sensitivity to the extinction coefficient of sunlight}

In order to investigate the importance of turbidity in the evolution of the lake surface water temperature, a sensitivity test of the FLake model to the water extinction coefficient was conducted.

The test consisted of FLake stand-alone simulations forced by atmospheric data collected at the Alqueva reservoir, using typical minimum and maximum expected extinction coefficients of $1.0 \mathrm{~m}^{-1}$ (clear water) and $6.1 \mathrm{~m}^{-1}$ (turbid water).

The model runs were carried out for May and June 2007 (61 days). In this period, the water column was thermally stratified. The forcing consists of time series of the hourly averaged meteorological variables - pressure, air moisture and temperature, wind speed, and solar global radiation collected at the Mourão meteorological station. This station belongs to the Portuguese Water Institute (INAG) and is installed on a floating platform located near the Mourão site (see Salgado and Le Moigne, 2010, for a description of this type of station). The data are available at the site http://snirh.pt. Since the downward longwave radiation flux is not measured at the station, though it is also needed, it was obtained from linear interpolation of the 3-hourly output of the ECMWF IFS weather forecast model.

The initial conditions were constructed from hourly water temperature observations collected at the same point. Unfortunately, the water temperature measurements are only available at 3 levels (surface, middle and bottom), which are not sufficient to adjust a FLake initial profile characterized by four variables. Thus, only the initial bottom temperature and the surface mixed layer temperature were taken directly from the observations. The other initial values $\left(C_{T}\right.$ and $\left.h\right)$ were obtained by tuning (calibrating) the model to reproduce the measured water surface temperature dataset. Due to the complex topographical characteristics of the artificial reservoir, the lake depth, $D$, which is not a local but an effective or spatially-averaged parameter, was also estimated by the tuning workout. In the tuning simulations, the value of the extinction coefficient corresponding to turbid water $\left(k=6.1 \mathrm{~m}^{-1}\right)$ was imposed. In the tuning process, 3 parameters were considered free (fixed depth, $D$, and initial values for $h$ and $C_{T}$ ). The model ran for an ensemble of realistic values for these variables: $D$ between 10 and $50 \mathrm{~m}$, with a step of $1 \mathrm{~m} ; h$ between 1 and $20 \mathrm{~m}$, step $1 \mathrm{~m} ; C_{T}$ between 0.50 and 0.80 (all range), step 0.01 . This means that about 24000 simulations were performed for the 61 day period. The configuration which minimized the root mean square error between modelled and observed hourly mean surface temperature was chosen. After this procedure, the following parameters and initial conditions were used: $D=23 \mathrm{~m}$, $T_{\mathrm{S}}=17.45^{\circ} \mathrm{C}, T_{\mathrm{BOT}}=14.35^{\circ} \mathrm{C}, h=4 \mathrm{~m}, C_{T}=0.79$. 
(a)

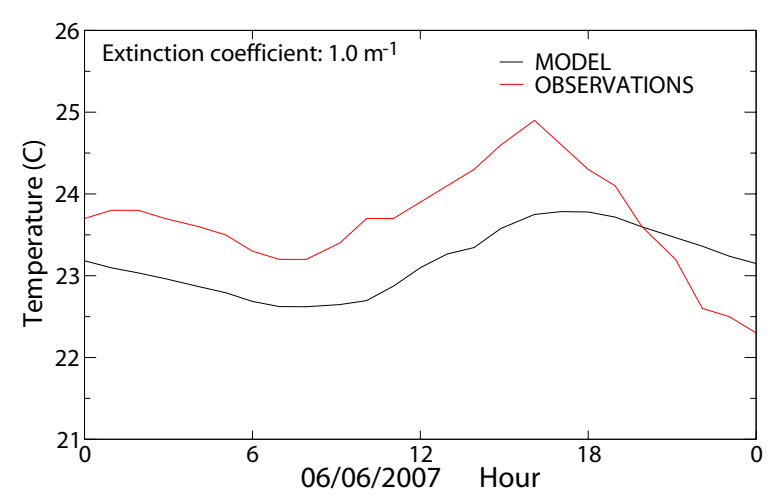

(c)

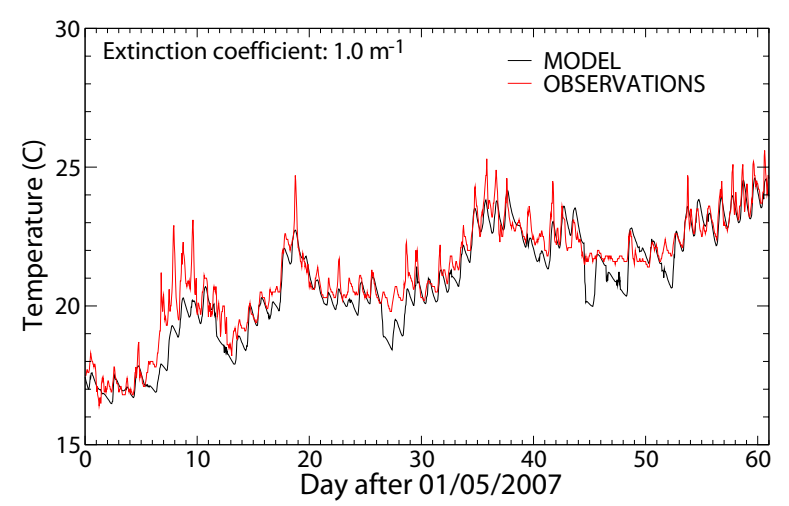

(b)

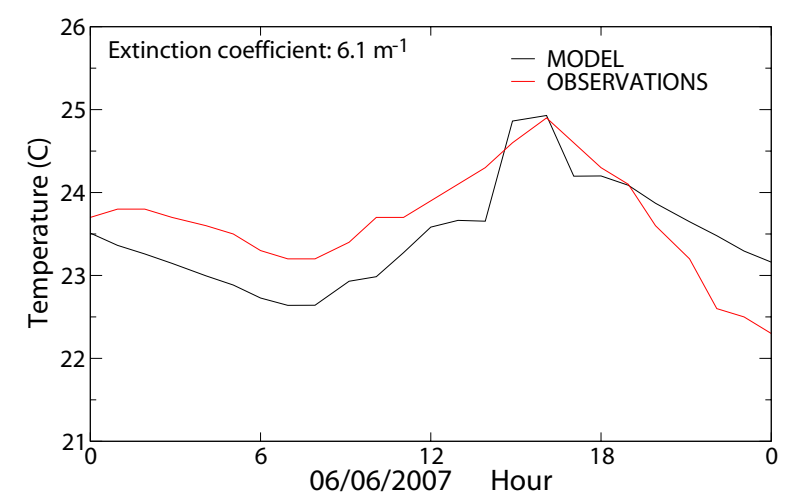

(d)

Water Temperature

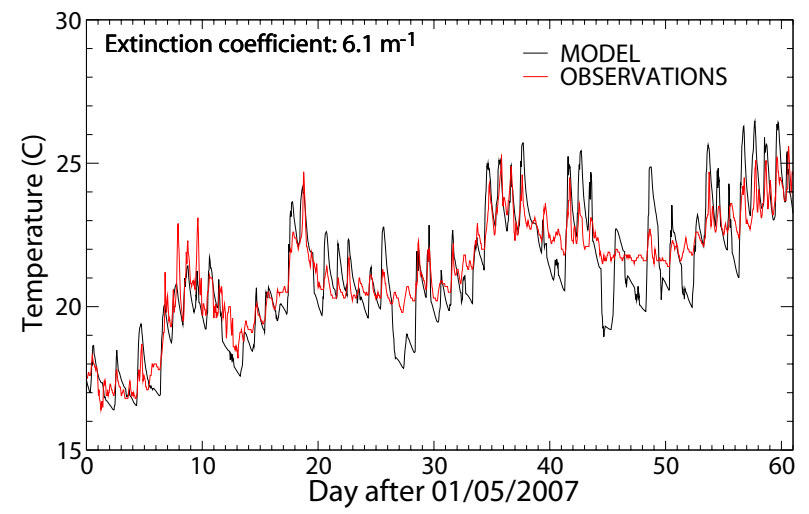

Fig. 6. Comparison between the lake water surface temperature observed and modeled with FLake for: (a) 6 June 2007 with an extinction coefficient of $1.0 \mathrm{~m}^{-1}$ (simulation Mo10); (b) 6 June 2007 with an extinction coefficient of $6.1 \mathrm{~m}^{-1}$ (simulation Mo61); (c) May and June 2007 with an extinction coefficient of $1.0 \mathrm{~m}^{-1}$ (simulation Mo10); (d) May and June 2007 with an extinction coefficient of $6.1 \mathrm{~m}^{-1}$ (simulation Mo61).

Each simulation was performed for 61 days using a time step of $30 \mathrm{~min}$. The initial conditions, the lake depth and the forcing were the same for all the simulations, which only differ on the extinction coefficient. Only the two extreme cases, corresponding to turbid and clear water values, of $k=6.1 \mathrm{~m}^{-1}$ (simulation Mo61) and $k=1.0 \mathrm{~m}^{-1}$ (simulation Mo10), will be analyzed and discussed. In the following, the simulations will be identified respectively by Mo61 and Mo10.

As expected and shown in Fig. 6a and b, the simulation Mo61 better reproduces the water surface diurnal cycle on 6 June (the day when the highest turbidity value was recorded); in particular, the modeled daily amplitude (around $2{ }^{\circ} \mathrm{C}$ ) is close to the observed one and higher than that obtained in the Mo10 (around $1^{\circ} \mathrm{C}$ ). In the late afternoon and evening, the observed water surface temperature dropped sharply due to the occurrence of strong wind, a feature not fully represented by the model, even in the Mo61 simulation.
The lower the coefficient of the extinction, the lower the daily temperature range is. This is visible on this particular day, and also during the entire period, as shown in Fig. 6c and $d$. The respective figures shows that surface temperature variations are more sudden in the Mo61 simulation. This is not an unexpected result, since when the water is more turbid, solar radiation will penetrate less deeply and therefore will be more absorbed in the surface layer, thereby heating it.

The results show that there are periods when the observed evolution is better reproduced by the simulation Mo61 (the first 10 days, for example), while, by contrast, others are better represented in the Mo10, corresponding to days with less thermal amplitude (days 45 to 55 , for example). It is possible that the periods best represented by the Mo61 simulation correspond to days of higher water turbidity and vice versa. Unfortunately, we lack a turbidity time series in order to confirm this assumption.

In any case, it can be concluded that the model is very sensitive to the extinction coefficient and that variations in turbidity (within the range of observed values) can lead to 
important differences in the lake surface temperature, which is a relevant parameter for heat and moisture transfers between water bodies and the atmosphere. Under the conditions assumed in the present sensitivity test, the daily mean surface temperature range jumps from about $1.2^{\circ} \mathrm{C}$ in the Mo10 (with a maximum of about $2.8^{\circ} \mathrm{C}$ ) to $2.4^{\circ} \mathrm{C}$ in the Mo61 (with a maximum of about $5.3^{\circ} \mathrm{C}$ ).

In both cases, but more clearly in the Mo61, the simulated surface (mixed layer) water temperatures show some events of sudden daily change not visible in the measured one. These events are initiated with a sharp fall in the surface layer temperature due, in the simulations, to the rapid increase of the mixed layer depth, $h$, which passes (in Mo61) from values less than $2 \mathrm{~m}$ to values greater than $8 \mathrm{~m}$ (not shown). Thus, the decrease in simulated temperature is due to the fact that the mixture brings deeper (colder) water to the surface. In turn, $h$ increases due to the occurrence of high speed wind events (greater than $10 \mathrm{~m} \mathrm{~s}^{-1}$ ).

In reality, this fact was not observed in the studied period. The difference between model and observations may be due to errors in wind measurements or, more likely, to horizontal mixtures not expected to be represented in 1-D models, which bring water from areas where the lake depth is lower than $h$ and therefore do not cool. Another explanation may be an incorrect representation of the evolution of $h$ in windy conditions when the lake water is very stratified. This possibility needs further investigation.

These differences in surface temperature have effects in the patterns of surface sensible heat flux, $H$, and evaporation, $E$. For the whole simulation period, the increase in simulated sensible heat flux between Mo10 and Mo61 is about $7 \%$. The simulated difference in total evaporation is relatively smaller, with the evaporation being about $3 \%$ higher for the simulation with higher turbidity (Mo61). The results thus indicate that more turbid lake waters tend, during the heating season, to prevent heating of the whole water column (leading to less heat storage) and transfer the energy faster to the atmosphere, resulting in a colder lake. In the end of the simulation period, the column mean water temperature is $0.3^{\circ} \mathrm{C}$ higher in Mo10 than in Mo61.

\section{Conclusions}

A satellite based methodology was developed and applied to retrieve the surface water turbidity of Alqueva reservoir in the south of Portugal. An important aspect of the satellite data used for surface applications is the atmospheric correction process. A validation of the atmospheric correction is presented based on the comparison between ground based and atmospherically corrected spectral reflectance measurements obtained during three field campaigns carried out in Alqueva throughout 2010 and early 2011. A correlation coefficient of 0.84 and a NRMSE of $14 \%$ were obtained for the comparison, which were deemed adequate, especially when compared to different atmospheric correction algorithms that are probably not suited for the Alqueva lake area.

The empirical algorithm proposed to estimate surface water turbidity from atmospherically corrected satellite spectral reflectance is of linear type and combines green $(560 \mathrm{~nm})$ and blue $(412.5 \mathrm{~nm})$ spectral regions, presenting a high correlation coefficient of 0.96 . Since only 17 data points were available for the study, new field campaigns are planned for Alqueva reservoir including turbidity as well as spectral reflectance and light extinction measurements. This is aimed at strengthening the confidence on the turbidity algorithm proposed, extending the turbidity limits and deriving a proper relation for the Alqueva lake extinction coefficient. Nevertheless, the turbidity spatial distribution obtained for the whole lake, for a case study, provided meaningful results.

A sensitivity study of the FLake model to the water extinction coefficient was also conducted in order to investigate the importance of turbidity in the evolution of the lake surface water temperature. Results show that the model is very sensitive to different extinction coefficient values and that variations in turbidity can lead to significant changes in the lake surface temperature, which is a parameter that plays a central role in heat and moisture transfers between the lake and the atmosphere. The results also indicate that the turbidity of water should be taken into account in lake schemes inside highresolution weather forecast models. While it is not possible to include this parameter in assimilation systems, we suggest the setup of time-dependent global climatological maps of the light extinction coefficient of lake waters be used by the forecast models. Those maps may be built following the satellite based methodology described in this work.

Acknowledgements. This work is financed through FEDER (Programa Operacional Factores de Competitividade - COMPETE) and National funding through FCT - Fundação para a Ciência e a Tecnologia in the framework of projects FCOMP-01-0124FEDER-007122 (PTDC/CTE-ATM/65307/2006) and FCOMP01-0124-FEDER-009303 (PTDC/CTE-ATM/102142/2008) and through FCT grant SFRH/BD/45577/2008. Image data has been provided by ESA in the frame of ENVISAT projects AOPT-2423 and AOPT-2357. We thank AERONET investigators for their effort in establishing and maintaining Évora AERONET site. We also thank the Water Laboratory of the University of Évora for support in the field campaigns and EDIA for providing the water quality data used in this work. We are grateful to the Portuguese Institute of Meteorology and ECMWF for MARS database account.

Edited by: A. Ghadouani 


\section{References}

Alikas, K. and Reinart, A.: Validation of the MERIS products on large European lakes: Peipsi, Vänern and Vättern, Hydrobiologia, 599, 161-168, 2008.

Balsamo, G., Salgado, R., Dutra, E., Boussetta, S., Stockdale, T., and Potes, M.: On the contribution of lakes in predicting nearsurface temperature in a global weather forecasting model, Tellus A, 64, 15829, doi:10.3402/tellusa.v64i0.15829, 2012.

Bukata, R. P., Jerome, J. H., Kondratyev, K. Y., and Pozdnyakov, D. V.: Optical Properties and Remote Sensing of Inland and Coastal Waters, CRS Press, 135-250, 1995.

Chapman, D.: Water quality assessments: A guide to the use of biota, sediments and water in environmental monitoring, 2nd Edn. London, Chapman \& Hall, 651 pp., 1996.

Chen, Z., Hu, C., and Muller-Karger, F.: Monitoring turbidity in Tampa Bay using MODIS/Aqua 250-m imagery, Remote Sens. Environ., 109, 207-220, 2006.

Dickey, T., Lewis, M., and Chang, G.: Optical Oceanography: Recent advances and future directions using global remote sensing and in situ observations, Rev. Geophys., 44, RG1001, doi:10.1029/2003RG000148, 2006.

Doerffer, R. and Schiller, H.: MERIS Regional Coastal and Lake Case 2 Water Project - Atmospheric Correction ATBD, GKSS Research Center 21502 Geesthacht Version 1.0, 2008.

Duan, H., Zhang, Y., Zhang, B., Song, K., Wang, Z., Liu, D., and Li, F.: Estimation of chlorophyll- $a$ concentration and trophic states for inland lakes in Northeast China from Landsat TM data and field spectral measurements, Int. J. Remote Sens., 29, 767-786, 2008.

Dutra, E., Stepanenko, V. M., Balsamo, G., Viterbo, P., Miranda, P. M. A., Mironov, D., and Schär, C.: An offline study of the impact of lakes on the performance of the ECMWF surface scheme, Boreal Environ. Res., 15, 100-112, 2010.

Elias, T., Silva, A. M., Belo, N., Pereira, S., Formenti, P., Helas, G., and Wagner, F.: Aerosol extinction in a remote continental region of the Iberian Peninsula during summer, J. Geophys. Res., 111, D14204, doi:10.1029/2005JD006610, 2006.

ESA: MERIS Product Handbook, Issue 2.0, available at: http: //envisat.esa.int/handbooks/meris/ (last access: March 2008), 2008.

Friedl, G. and Wüest, A.: Disrupting biogeochemical cycles. Consequences of damming, Aquat. Sci., 64, 55-65, 2002.

Giblin, S., Hoff, K., Fischer, J., and Dukerschein, T.: Evaluation of light penetration on Navigation Pools 8 and 13 of the Upper Mississippi River, US Geological Survey Long Term Resource Monitoring Program Technical Report 2010-T001, 26 pp., 2010.

Gitelson, A. A., Dall'Olmo, G., Moses, W., Rundquist, D. C., Barrow, T., Fisher, T. R., Gurlin, D., and Holz, J.: A simple semianalytical model for remote estimation of chlorophyll-a in turbid waters: Validation, Remote Sens. Environ., 112, 3582-3593, 2008.

Gordon, H. R. and Wang, M.: Retrieval of water-leaving radiance and aerosol optical thickness over the oceans with SeaWiFS: A preliminary algorithm, Appl. Optics, 33, 443-452, 1994.

Gons, H. J., Auer, M. T., and Effler, S. W.: MERIS satellite chlorophyll mapping of oligotrophic and eutrophic waters in the Laurentian Great Lakes, Remote Sens. Environ., 112, 4098-4106, 2008.
Grobler, D. C., Toerien, D. F., and De Wet, J. S.: Changes in turbidity as a result of mineralization in the lower Vall River, Water SA, 9, 110-116, 1983.

Härmä, P., Vepsäläinen, J., Hannonen, T.P., Kämäri, J., Kallio, K., Eloheimo, K., and Koponen, S.: Detection of water quality using simulated satellite data and semi-empirical algorithms in Finland, Sci. Total Environ., 268, 107-121, 2001.

Holben, B. N., Tanre, D., Smirnov, A., Eck, T. F., Slutsker, I., Abuhassan, N., Newcomb, W. W., Schafer, J., Chatenet, B., Lavenue, F., Kaufman, Y. J., Vande Castle, J., Setzer, A., Markham, B., Clark, D., Frouin, R., Halthore, R., Karnieli, A., O'neill, N. T., Pietras, C., Pinker, R. T., Voss, K., and Zibordi, G.: An emerging ground-based aerosol climatology: Aerosol Optical Depth from AERONET, J. Geophys. Res., 106, 12067-12097, 2001.

Kheyrollah Pour, H., Duguay, C., Martynov, A., and Brown, L.: Simulation of surface temperature and ice cover of large northern lakes with 1-D models: a comparison with MODIS satellite data and in situ measurements, Tellus A, 64, 17614, doi:10.3402/tellusa.v64i0.17614, 2012.

Koponen, S., Pulliainen, J., Kallio, K., and Hallikainen, M.: Lake water quality classification with airborne hyperspectral spectrometer and simulated MERIS data, Remote Sens. Environ., 79, 51-59, 2002.

Lee, R. W. and Walter, R.: Light attenuation in a shallow, turbid reservoir, lake Houston, Texas, US Geological Survey, WaterResources Investigations Report 97-4064, 1997.

Lloyd, D. S., Koenings, J. P., and Laperriere, J. D.: Effects of Turbidity in Fresh Waters of Alaska, N. Am. J. Fish. Manage., 7, 18-3, 1987.

Michaud, J. P.: A citizen's guide to understanding and monitoring lakes and streams, Publ. \#94-149, Washington State Dept. of Ecology, Publications Office, Olympia, WA, USA (360) $407-$ 7472, 1991.

Mironov, D. V.: Parameterization of lakes in numerical weather prediction. Description of a lake model, COSMO Technical Report 11, Deutscher Wetterdienst, Offenbach am Main, Germany, 41 pp., 2008.

Mironov, D. V., Rontu, L., Kourzeneva, E., and Terzhevik, A.: Towards improved representation of lakes in numerical weather prediction and climate models: Introduction to the special issue of Boreal Environment Research, Boreal Environ. Res., 15, $97-$ 99, 2010.

Moore, G. K.: Satellite remote sensing of water turbidity, Hydrolog. Sci. J., 25, 407-421, 1980.

Morais, M., Serafim, A., Pinto, P., Ilhéu, A., and Ruivo, M.: Monitoring the water quality in Alqueva Reservoir, Guadiana River, southern Portugal, Reservoir and River Basin Management, Exchange of Experiences from Brazil, Portugal and Germany, edited by: Gunkel, G. and Sobral, M., 2007.

Oliver, R. L., Hart, B. T., Olley, J., Grace, M., Rees, C., and Caitcheon, G.: The Darling River: Algal Growth and the Cycling and Sources of Nutrients, Final report to the Murray-Darling Basin Commission, 1999.

Parkhill, K. L. and Gulliver, J. S.: Effect of inorganic sediment on whole stream productivity, Hydrobiologia, 472, 5-17, 2002.

Potes, M., Costa, M. J., Silva, J. C. B., Silva, A. M., and Morais, M.: Remote sensing of water quality parameters over Alqueva reservoir in the south of Portugal, Int. J. Remote Sens., 32, 3373 3388, 2011. 
Roos, J. C. and Pieterse, J. H.: Light, temperature and flow regimes of the Vaal River at Balkfontein, South Africa, Hydrobiologia, 277, 1-15, 1994.

Salgado, R. and Le Moigne, P.: Coupling of the FLake model to the Surfex externalized surface model, Boreal Environ. Res., 15, 231-244, 2010.

Sathyendranath, S.: Remote sensing of ocean colour in coastal, and other optically-complex, waters, In Reports of the International Ocean-Colour Coordinating Group, 3rd Edn., IOCCG, Dartmouth, Canada, 2000.

Simis, S., Ruiz-Verdú, A., Domínguez-Gómez, J. A., PeñaMartinez, R., Peters, S., and Gons, H. J.: Influence of phytoplankton pigment composition on remote sensing of cyanobacterial biomass, Remote Sens. Environ., 106, 414-427, 2007.
Tyler, A. N., Svab, E., Preston, T., Preacutesing, M., and Kovaacutecs, W. A.: Remote sensing of the water quality of shallow lakes: A mixture modelling approach to quantifying phytoplankton in water characterized by high-suspended sediment, Int. J. Remote Sens., 27, 1521-1537, 2006.

Vermote, E. F., Tanré, D., Deuzé, J.-L., Herman, M., and Morcrette, J.-J.: Second simulation of the satellite signal in the solar spectrum: An overview, IEEE T. Geosci. Remote., 35, 675-686, 1997.

Zilitinkevich, S. S. (Ed.), Ferdorovich, E. E., Golosov, S. D., Kreiman, K. D., Mironov, D. V., Shabalova, M. V., and Terzhevik, A. Y.: Modeling Air-Lake Interaction. Physical Background, Springer Verlag, Berlin, 130 pp., 1991. 